\title{
Insulin resistance and daytime sleepiness in patients with sleep apnoea
}

\author{
A Barceló, ${ }^{1}$ F Barbé, ${ }^{2} \mathrm{M}$ de la Peña, ${ }^{3}$ P Martinez, ${ }^{4} \mathrm{~J}$ B Soriano, ${ }^{4} \mathrm{~J}$ Piérola, ${ }^{5}$ \\ A G N Agustíi,4,6
}

\section{See Editorial, p 939}

${ }^{1}$ Servei de Anàlisis Cliniques, Hospital Universitari Son Dureta, Palma de Mallorca, Spain;

${ }^{2}$ Servei de Pneumologia, Hospital Arnau de Vilanova, Lleida, Spain; ${ }^{3}$ Servei de

Pneumologia, Hospital Universitari Son Dureta, Palma de Mallorca, Spain; ${ }^{4}$ Fundació Caubet-Cimera, Illes Balears, Lleida, Spain; ${ }^{5}$ Unitat de Investigació, Hospital Universitari Son Dureta, Palma de Mallorca, Spain; ${ }^{6}$ CIBER Enfermedades Respiratorias, Lleida, Spain

Correspondence to: Dr A Barceló, Servei de Analisis Cliniques, Hospital Universitari Son Dureta, C/ Andrea Doria 55 07014 Palma de Mallorca, Spain; abarcelo@hsd.es

Received 20 November 2007 Accepted 30 April 2008

Published Online First

5 June 2008

\begin{abstract}
Background: Excessive daytime sleepiness (EDS), obesity and insulin resistance (IR) occur frequently in patients with obstructive sleep apnoea syndrome (OSAS). We hypothesised that in these patients, EDS is a marker of $I R$, independent of obesity.
\end{abstract}

Methods: We studied 44 patients with OSAS (22 with and 22 without EDS) matched for age ( \pm 5 years), body mass index $\left(\mathrm{BMl} \pm 3 \mathrm{~kg} / \mathrm{m}^{2}\right.$ ) and severity of OSAS (as determined by the apnoea-hypopnoea index (AHI)), and 23 healthy controls. Patients $(n=35)$ were re-examined after 3 months of effective therapy with continuous positive airway pressure (CPAP). EDS was assessed by both subjective (Epworth Sleepiness Scale) and objective (Multiple Sleep Latency Test) methods. IR was determined by the HOMA index. Serum levels of glucose, triglycerides, cholesterol, cortisol, insulin, thyrotropin, growth hormone and insulin-like growth factor I (IGF-I) were also determined.

Results: Despite the fact that age, BMI and AHI were similar, patients with EDS had higher plasma levels of glucose $(p<0.05)$ and insulin $(p<0.01)$, as well as evidence of $I R(p<0.01)$ compared with patients without EDS or healthy controls. CPAP treatment reduced cholesterol, insulin and the HOMA index and increased IGF-1 levels in patients with EDS, but did not modify any of these variables in patients without EDS.

Conclusion: EDS in OSAS is associated with $\mathbb{R}$, independent of obesity. Hence EDS may be a useful clinical marker to identify patients with OSAS at risk of metabolic syndrome.

The obstructive sleep apnoea syndrome (OSAS) is a common disorder defined by the occurrence of repeated episodes of upper airway obstruction and airflow cessation (apnoeas) that normally lead to arterial hypoxaemia and sleep disruption. ${ }^{1}$ A number of clinical features, such as obesity, excessive daytime sleepiness (EDS) and insulin resistance (IR), are often but not invariably present in these patients. ${ }^{2-7}$

The relationship between obesity, IR and EDS in patients with OSAS is complex and poorly understood. ${ }^{8-10}$ Obesity is generally regarded as a risk factor for both OSAS and IR. ${ }^{11}{ }^{12}$ However, factors other than obesity appear to play a significant role in the development of IR and metabolic disturbances in patients with OSAS, ${ }^{813-16}$ including sleep fragmentation, increased sympathetic activity and intermittent hypoxia. ${ }^{17-21}$ On the other hand, experimental evidence shows that intermittent hypoxaemia during sleep triggers neural damage to brain regions that promote and control wakefulness through a convergence of oxidative and inflammatory events that ultimately lead to neuronal cell loss and EDS. ${ }^{22}{ }^{23}$

In this study, we hypothesised that EDS in OSAS is associated with IR, independent of obesity, and that the abolishment of nocturnal apnoeas by continuous positive airway pressure (CPAP) therapy improves both EDS and IR. To test this hypothesis, we studied two groups of patients with OSAS (22 each) who were carefully matched for severity of OSAS, obesity and age, but who were clearly different in terms of the presence or absence of EDS. Patients were studied at diagnosis and 3 months after being effectively treated with CPAP.

\section{METHODS}

\section{Subjects and ethics}

We included in the study 44 male patients with OSAS (22 with EDS and 22 without EDS). Patients were matched for age ( \pm 5 years), body mass index $\left(\mathrm{BMI} \pm 3 \mathrm{~kg} / \mathrm{m}^{2}\right)$ and severity of OSAS (as determined by the apnoea-hypopnoea index (AHI)). As a reference group, we studied 23 healthy, nonobese males of similar age who had never smoked. No participant suffered from any other chronic disease (chronic obstructive pulmonary disease, diabetes mellitus, liver cirrhosis, thyroid dysfunction, rheumatoid arthritis, chronic renal failure and/or psychiatric disorders) or was taking any type of medication. The study was approved by the ethics committee of our institution, and all participants signed their consent after being fully informed of its goal and characteristics.

\section{Design}

Each patient was studied at diagnosis and after effective treatment with CPAP (REM Star; Respironics, Murrysville, Pennsylvania, USA) for 3 months. Compliance with treatment was checked by the timer built up in the CPAP device. Nine patients (two with and seven without EDS) who did not use the device for a minimum of $4 \mathrm{~h} /$ night were excluded from the follow-up analysis. After fasting overnight, venous blood samples were obtained between 08:00 and 10:00. Blood was centrifuged and serum was immediately separated in aliquots and stored at $-80^{\circ} \mathrm{C}$ until analysis.

\section{Measurements and definitions}

The diagnosis of OSAS was established by full polysomnography (E-Series Compumedics, Abbotsford, Australia) that included recording of oronasal flow, thoracoabdominal movements, electrocardiography, submental and pretibial 
Table 1 Subject characteristics

\begin{tabular}{|c|c|c|c|c|}
\hline & $\begin{array}{l}\text { OSAS with EDS } \\
(n=22)\end{array}$ & $\begin{array}{l}\text { OSAS without EDS } \\
(n=22)\end{array}$ & $\begin{array}{l}\text { Healthy subjects } \\
(n=23)\end{array}$ & p Value $(a, b, c)$ \\
\hline Age (y) & 49 (6) (46 to 52$)$ & 50 (5) (46 to 52$)$ & $48(6)(45$ to 50$)$ & $0.535,0.142,0.061$ \\
\hline BMI $\left(\mathrm{kg} / \mathrm{m}^{2}\right)$ & 32 (3) (30 to 34$)$ & 31 (4) (28 to 34$)$ & 25 (3) (24 to 27$)$ & $0.000,0.230,0.000$ \\
\hline Hypertension (\%) & 55 & 65 & 0 & \\
\hline $\mathrm{SBP}(\mathrm{mm} \mathrm{Hg})$ & 139 (13) (135 to 146$)$ & 147 (22) (137 to 157$)$ & 128 (9) (124 to 132$)$ & $0.010,0.115,0.001$ \\
\hline $\mathrm{DBP}(\mathrm{mm} \mathrm{Hg})$ & 92 (10) (88 to 96$)$ & 93 (11) (89 to 97) & 78 (8) (75 to 82$)$ & $0.000,0.622,0.000$ \\
\hline Current smoker (\%) & 48 & 40 & 0 & \\
\hline $\mathrm{AHI}(/ \mathrm{h})$ & 52 (19) (44 to 60$)$ & 48 (16) (40 to 56$)$ & $3(1)(1$ to 4$)$ & $0.000,0.396,0.000$ \\
\hline Mean $\mathrm{SaO}_{2}(\%)$ & $86(6)(84$ to 89$)$ & 90 (5) (87 to 94$)$ & 93 (2) (92 to 95$)$ & $0.000,0.040,0.040$ \\
\hline Minimal $\mathrm{SaO}_{2}(\%)$ & 69 (12) (64 to 75) & 81 (8) (75 to 86$)$ & NA & 0.010 \\
\hline ESS & 16 (3) (15 to 18$)$ & 4 (3) (3 to 7) & $3(2)(1$ to 5$)$ & $0.000,0.000,0.06$ \\
\hline MSLT (min) & $5(3)$ (3 to 7$)$ & 15 (3) (13 to 17$)$ & NA & 0.000 \\
\hline Arousal index & 65 (19) (55 to 73 ) & $62(25)(56$ to 71$)$ & NA & 0.732 \\
\hline
\end{tabular}

electromyography, electrooculography, electroencephalography and trancutaneous measurement of arterial oxygen saturation. Apnoea was defined by the absence of airflow for more than $10 \mathrm{~s}$. Hypopnoea was defined as any airflow reduction that lasted more than $10 \mathrm{~s}$ and resulted in arousal or oxygen desaturation. We considered desaturation as a decrease in arterial oxygen saturation greater than $4 \%$. AHI was defined as the sum of the number of apnoeas plus hypopnoeas per hour of sleep. In healthy subjects, the diagnosis of OSA was excluded by a cardiorespiratory sleep study that recorded nasal flow, thoracic movements, heart rate, snoring, body position and transcutaneous oxyhaemoglobin saturation (Edentec, Minnesota, USA).

EDS was quantified subjectively by the Epworth Sleepiness Scale (ESS) and objectively by the Multiple Sleep Latency Test (MSLT). In order to have two well characterised groups, we defined EDS by the coexistence of an ESS >10 and an MSLT $<5$ min. Likewise, absence of EDS was defined when ESS was $<10$ and the MSLT $>10 \mathrm{~min}$.

Arterial hypertension was diagnosed if systolic blood pressure (SBP) was $>140 \mathrm{~mm} \mathrm{Hg}$ or diastolic pressure (DBP) was $>90 \mathrm{~mm} \mathrm{Hg}$. Glucose, triglycerides, total cholesterol and high density lipoprotein cholesterol (HDLc) were determined by standard enzymatic methods on a Hitachi Modular analyser (Roche Diagnostics, Indianapolis, USA). Plasma concentrations of insulin, thyrotropin (TSH), cortisol, growth hormone (GH) and insulin-like growth factor I (IGF-I) were measured by commercial chemiluminescent assays on a Immulite 2000 analyser (GH, insulin and IGF-I) or Advia Centaur analyser (TSH and cortisol) (Siemens Medical Solutions Diagnostics, New York, USA). Insulin resistance was calculated using the Homeostasis Model Assessment (HOMA) index. ${ }^{24}$

\section{Statistical analysis}

Results are shown as mean (SD). One way ANOVA, followed by post hoc contrast if appropriate, was used to assess the statistical significance of differences between groups. Correlations between variables were explored using the Spearman rank test. The effects of CPAP therapy were analysed using paired t tests. A $p$ value $<0.05$ was considered significant.

\section{RESULTS}

Table 1 shows the main characteristics of the subjects studied. By design, age, BMI and AHI were similar in patients with and without EDS. Also by design, patients with EDS showed higher ESS and lower MSLT values than the other two groups.

Table 2 Metabolic markers determined at baseline in healthy subjects and in patients with OSAS, with and without EDS

\begin{tabular}{|c|c|c|c|c|}
\hline & $\begin{array}{l}\text { OSAS with EDS } \\
(n=22)\end{array}$ & $\begin{array}{l}\text { OSAS without EDS } \\
(n=22)\end{array}$ & $\begin{array}{l}\text { Healthy subjects } \\
(\mathrm{n}=23)\end{array}$ & p Value $(a, b, c)$ \\
\hline Glucose (mg/dl) & 115 (19) (107 to 122 ) & $103(20)(94$ to 113$)$ & 99 (8) (95 to 103) & $0.002,0.032,0.039$ \\
\hline Triglycerides (mg/dl) & $199(110)$ (157 to 241$)$ & $153(58)$ (126 to 179$)$ & $128(93)$ (88 to 169$)$ & $0.008,0.084,0.395$ \\
\hline Cholesterol (mg/dl) & $223(34)(210$ to 237$)$ & $220(50)(197$ to 243$)$ & $224(30)(221$ to 237$)$ & $0.960,0.742,0.721$ \\
\hline $\mathrm{HDLc}(\mathrm{mg} / \mathrm{dl})$ & 46 (10) (42 to 50$)$ & $56(11)(50$ to 61$)$ & 52 (9) (47 to 56$)$ & $0.055,0.002,0.189$ \\
\hline Insulin $(\mu \mathrm{U} / \mathrm{ml})$ & $15.2(7.6)(12.3$ to 18.1$)$ & $8.6(4.8)(6.4$ to 10.8$)$ & $7.8(3.0)(6.5$ to 9.2$)$ & $0.000,0.000,0.664$ \\
\hline HOMA index & $4.3(2.4)(3.4$ to 5.3$)$ & $2.3(1.8)(1.5$ to 3.2$)$ & $1.9(0.8)(1.6$ to 2.3$)$ & $0.000,0.000,0.510$ \\
\hline TSH ( $\mu U \mathrm{l} / \mathrm{ml})$ & $1.1(0.5)(0.9$ to 1.3$)$ & $1.6(1.1)(1.1$ to 2.1$)$ & $1.5(1.1)(1.1$ to 2.0$)$ & $0.120,0.093,0.872$ \\
\hline Cortisol (mg/dl) & $13.4(5.0)(11.5$ to 15.4$)$ & $15.5(4.2)(13.6$ to 17.4$)$ & $14.3(3.4)(12.9$ to 15.8$)$ & $0.448,0.099,0.382$ \\
\hline $\mathrm{GH}(\mathrm{ng} / \mathrm{ml})$ & $0.38(0.13)(-0.14$ to 0.90$)$ & $0.15(0.14)(0.07$ to 0.21$)$ & $0.17(0.16)(0.09$ to 0.23$)$ & $0.389,0.347,0.922$ \\
\hline IGF-1 (ng/ml) & $121(94)$ (86 to 157$)$ & 106 (27) (94 to 118 ) & $122(36)(107$ to 138$)$ & $0.946,0.410,0.398$ \\
\hline
\end{tabular}

Results are presented as mean (SD) (95\% confidence interval for the mean).

$p$ values: $a=$ OSAS with EDS vs controls; $b=$ OSAS with EDS vs OSAS without EDS; $c=0$ OSAS without EDS vs controls.

EDS, excessive daytime sleepiness; $\mathrm{GH}$, growth hormone; HDLc, high density lipoprotein cholesterol; HOMA, homeostasis model assessment; IGF-1, insulin-like growth factor I; OSAS, obstructive sleep apnoea syndrome; TSH, thyrotropin. 
Figure 1 Relationship between homeostasis model assessment (HOMA) index and (A) multiple sleep latency time (MSLT), (B) Epworth Sleepiness Scale (ESS), (C) arousal index and (D) mean nocturnal oxygenation saturation $\left(\mathrm{SaO}_{2}\right)$ in patients with obstructive sleep apnoea syndrome. For further explanations see text.
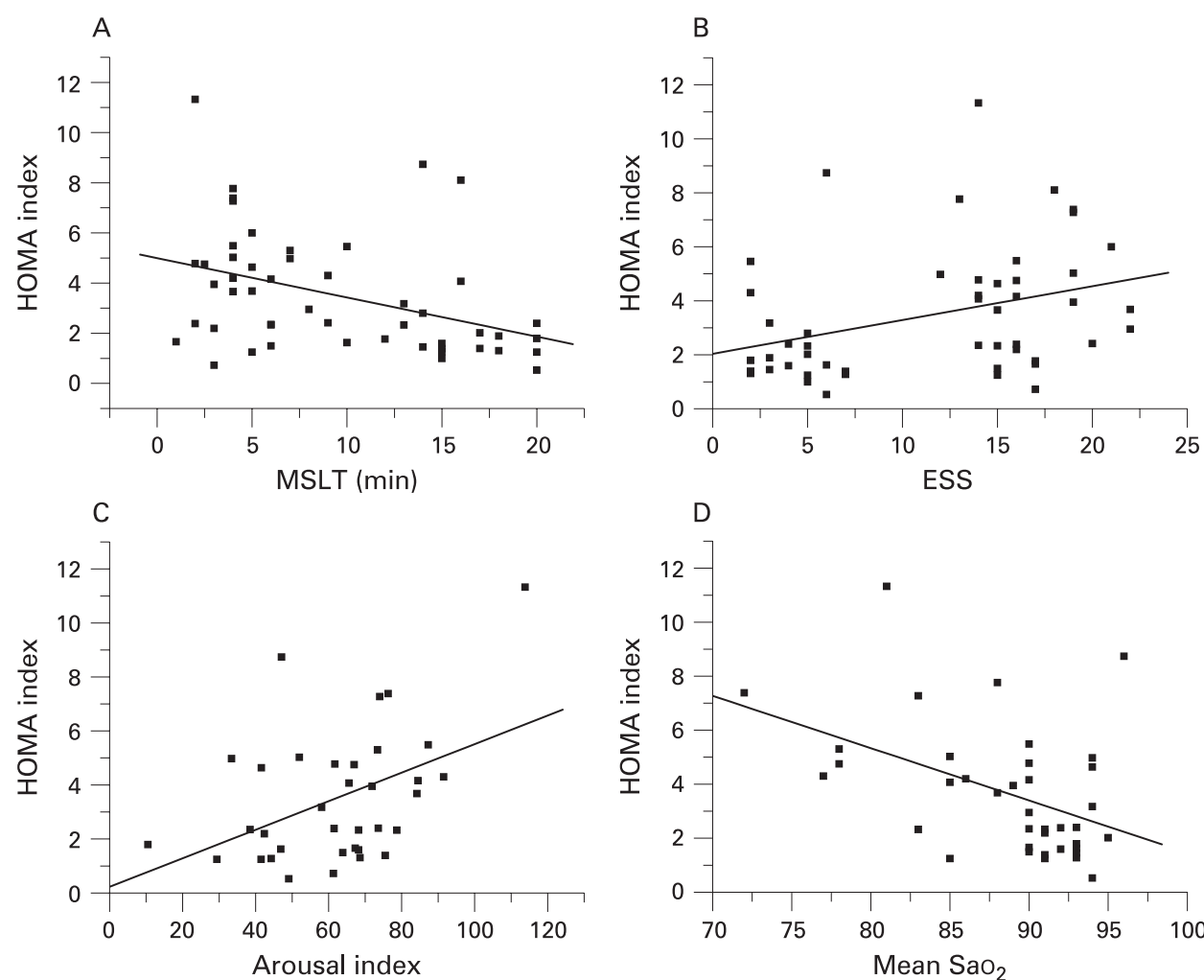

Interestingly, despite similar BMI and AHI, nocturnal oxygenation indices (mean and minimum oxygen saturation) were significantly worse in the EDS group (table 1).

Compared with healthy subjects, patients with OSAS with EDS showed abnormal plasma levels of glucose, HDLc and insulin, as well as evidence of IR (higher HOMA index) (table 2). In contrast, despite having a similar AHI and BMI, these values were not different in patients without EDS and healthy controls (table 2). TSH, cortisol, GH and IGF-1 levels were similar between groups (table 2).

Insulin resistance (as determined by the HOMA index) was significantly related to EDS, determined both objectively by the $\operatorname{MSLT}(r=-0.434, p=0.002)$ and subjectively by the ESS $(\mathrm{r}=0.344, \mathrm{p}=0.015)$ (fig $1 \mathrm{~A}$ and $\mathrm{B}$, respectively).
Interestingly, insulin resistance was also significantly related to the arousal index $(r=0.341, p=0.042)$, and mean $(\mathrm{r}=-0.342, \mathrm{p}=0.033)$ (fig $1 \mathrm{C}$ and $\mathrm{D}$, respectively) and minimal nocturnal oxygenation saturation $(r=-0.359, p=0.047)$.

Table 3 presents the effects of CPAP therapy on a number of metabolic markers.

Nine patients were excluded from the analysis of the effects of CPAP because average therapeutic compliance was lower than $4 \mathrm{~h} /$ night. Mean CPAP use in compliant patients was 5.5 (1.3 h/night (in 20 those with EDS)) and 5.7 (1.3 h/night (in 15 those without EDS)). In patients with EDS, CPAP treatment reduced cholesterol, insulin and IR (HOMA index) and it increased IGF-1 levels. In contrast, in patients with OSAS without EDS, CPAP therapy did not influence these variables

Table 3 Effects of CPAP in patients with OSAS with and without EDS

\begin{tabular}{|c|c|c|c|c|c|c|}
\hline & \multicolumn{2}{|c|}{ OSAS with EDS $(n=20)$} & \multicolumn{2}{|c|}{ OSAS without EDS $(n=15)$} & \multirow{2}{*}{$\begin{array}{l}\text { Differences in } \\
\text { after-before } \\
\text { CPAP between patients } \\
\text { with and without EDS } \\
\text { (95\% CI) }\end{array}$} & \multirow[b]{2}{*}{ p Value } \\
\hline & Before CPAP & After CPAP & Before CPAP & After CPAP & & \\
\hline Glucose (mg/dl) & $114(19)$ & $111(22)$ & $101(6)$ & $100(9)$ & $-2.1(-7.8$ to 3.5$)$ & 0.44 \\
\hline Triglycerides (mg/dl) & 206 (114) & $218(121)$ & $157(54)$ & $149(61)$ & $20.8(-18.6$ to 60.3$)$ & 0.29 \\
\hline Cholesterol (mg/dl) & $224(34)$ & $211(29)^{*}$ & $214(41)$ & $206(41)$ & $-4.1(-21.7$ to 13.5$)$ & 0.63 \\
\hline HDLc (mg/dl) & $46(10)$ & $44(7)$ & $53(10)$ & $50(9)$ & $1.91(-1.6$ to 5.4$)$ & 0.27 \\
\hline Insulin $(\mu \mathrm{U} / \mathrm{ml})$ & $14.8(7.9)$ & $12.0(5.0)^{*}$ & $9.0(4.8)$ & $9.5(4.7)$ & $-3.3(-6.5$ to -0.2$)$ & 0.03 \\
\hline HOMA index & $4.4(2.4)$ & $3.3(1.3)^{* *}$ & $2.3(1.2)$ & $2.4(1.2)$ & $-1.2(-2.1$ to -0.3$)$ & 0.007 \\
\hline $\mathrm{TSH}(\mathrm{uUl} / \mathrm{ml})$ & $1.2(0.5)$ & $1.1(0.6)$ & $1.4(0.6)$ & $1.4(0.7)$ & $0.01(-0.22$ to 0.25$)$ & 0.89 \\
\hline Cortisol (mg/dl) & $13.1(5.1)$ & $12.3(4.9)$ & $15.0(3.8)$ & $12.5(2.4)$ & $1.6(-1.2$ to 4.5$)$ & 0.26 \\
\hline $\mathrm{GH}(\mathrm{ng} / \mathrm{ml})$ & $0.42(0.28)$ & $0.45(0.37)$ & $0.14(0.11)$ & $0.07(0.05)$ & $0.09(-0.11$ to 0.29$)$ & 0.35 \\
\hline IGF-1 (ng/ml) & 122 (99) & $145(134)^{*}$ & $113(25)$ & $127(28)$ & $14.1(-13.3$ to 41.5$)$ & 0.30 \\
\hline
\end{tabular}

${ }^{*} p<0.05,{ }^{*} p<0.01$ versus before CPAP.

CPAP, continuous positive airway pressure; EDS, excessive daytime sleepiness; GH, growth hormone; HDLc, high density lipoprotein cholesterol; HOMA, homeostasis model assessment; IGF-1, insulin-like growth factor I; OSAS, obstructive sleep apnoea syndrome; TSH, thyrotropin. 
(table 3). As a result, there was a differential effect of CPAP in patients with and without EDS for insulin levels $(p=0.03)$ and HOMA index values $(p=0.007)$. We did not find any significant correlation between the number of hours of CPAP usage and the change in IR whether all patients were analysed $(r=0.076$, $\mathrm{p}=0.669)$ or if only patients with EDS were included $(\mathrm{r}=-0.167, \mathrm{p}=0.416)$. There was a small but non-significant change in blood pressure between patients with and without EDS (systolic blood pressure $-2.2 \mathrm{~mm} \mathrm{Hg}$ (95\% CI -3.8 to 5.7), $\mathrm{p}=0.403$; diastolic pressure $-0.8 \mathrm{~mm} \mathrm{Hg}(95 \% \mathrm{CI}:-3.7$ to 5.4$)$, $\mathrm{p}=0.708)$

\section{DISCUSSION}

This study shows that EDS is a marker of IR in patients, independent of obesity. It also shows that in patients with OSAS and EDS, CPAP therapy improves both EDS and IR. These findings suggest that EDS is a potentially useful clinical marker to identify patients with OSAS at risk of metabolic syndrome.

\section{Previous studies}

The relationship between OSAS, obesity, EDS and IR is complex and unclear. ' Several studies found an association between OSAS and IR, ${ }^{10}{ }^{16}{ }^{25-27}$ but others failed to do so. ${ }^{28} 29$ Likewise, the reported effects of CPAP treatment on glucose metabolism are contradictory. ${ }^{13}{ }^{30-32}$ Finally, EDS is a frequent, but not universal, symptom in patients with OSAS ${ }^{33}$ and recent evidence suggest that EDS may be an independent risk factor for diabetes. ${ }^{34}$ In this study, we hypothesised that EDS was associated with IR in OSAS, independent of obesity, and that CPAP therapy improves both conditions. Our results confirm this hypothesis. The fact that EDS is also a marker of blood pressure response to CPAP therapy in patients with OSAS ${ }^{33} 35$ suggests that EDS is a potentially relevant clinical marker of several clinical manifestations of OSAS.

\section{Mechanisms}

The most salient finding of our study is that EDS is associated with IR in patients with OSAS, independent of obesity. This statement is further supported by the observation that the improvement in IR by CPAP therapy in patients with EDS occurred in the absence of any change in BMI. To explain these observations, we propose two potential mechanisms. Firstly, we speculate that EDS and IR in OSAS may share common pathogenic mechanisms, such as is tissue hypoxia. The fact that patients with EDS had lower mean and minimal nocturnal oxygenation saturation than patients without EDS, despite similar BMI and AHI values, supports this hypothesis (table 1). Furthermore, we found a significant correlation between insulin levels and HOMA values and indices of nocturnal hypoxaemia and arousal index, suggesting that nocturnal hypoxaemia may influence both EDS and IR in OSAS. This interpretation would be in keeping with previous findings from our laboratory. ${ }^{36}$ Secondly, it is also possible that EDS can contribute by itself to IR and that patients with EDS represent a particular OSAS phenotype.

The role of IGF-1 in glucose metabolism regulation is debated, ${ }^{37}$ but several studies have shown that insulin sensitivity and glucose tolerance improve after infusion of IGF-1. ${ }^{38}{ }^{39}$ In our study, we observed that IGF-1 levels tended to be reduced in patients without EDS, compared with patients with EDS and also with healthy subjects (although the differences failed to achieve statistical significance) (table 2). Interestingly, treatment with CPAP was followed by a rise in IGF-1 levels in both groups, although this was significant only in those patients with EDS, in whom IR was also improved (table 3). Other previous studies have also shown that treatment with CPAP for 3 weeks is followed by a rise in IGF-1 concentrations. ${ }^{30}$ Thus the IGF-1 system may represent a compensatory mechanism to the presence of IR in patients with OSAS.

\section{Limitations}

Some potential confounding factors, such as abdominal obesity, nutritional status, physical activity or the interaction between genetic variants, were not taken into account in our analysis. Despite the fact that patients with and without EDS were matched for BMI, this does not exclude potential differences in body fat distribution. Therefore, our results require confirmation in large populations in whom these confounders are adequately controlled.

\section{CONCLUSIONS}

This study shows that EDS is associated with IR, independent of obesity, in patients with OSAS, and that treatment with CPAP improves IR and EDS in these patients. These results have implications for a better understanding of the pathogenesis of IR in OSAS but also for the clinical management of these patients as they suggest that the presence of EDS may be a useful clinical indicator of the presence of metabolic abnormalities in OSAS.

Funding: Supported in part by ABEMAR, SEPAR and Fondo de Investigaciones Sanitarias (04/1593)

Competing interests: None declared.

Ethics approval: Ethics approval was obtained.

\section{REFERENCES}

1. Douglas NJ, Polo 0. Pathogenesis of sleep apnoea/hypopnoea syndrome. Lancet 1994;344:653-5.

2. Young T, Palta M, Dempsey J, et al. The occurrence of sleep-disordered breathing among middle-aged adults. N Engl J Med 1993;328:1230-5.

3. Redline S, Tishler PV. The genetics of sleep apnea. Sleep Med 2000:4:583-602.

4. Young T, Peppard PE, Gottlieb DJ. Epidemiology of obstructive sleep apnea: a population health perspective. Am J Respir Crit Care Med 2002;165:1217-39.

5. Duran J, Esnaola S, Rubio R, et al. Obstructive sleep apnea-hypopnea and related clinical features in a population-based sample of subjects aged 30 to $70 \mathrm{yr}$. Am J Respir Crit Care Med 2001;163:685-9.

6. Tasali $\mathbf{E}$, Ip MS. Obstructive sleep apnea and metabolic syndrome: alterations in glucose metabolism and inflammation. Proc Am Thorac Soc 2008;5:207-17.

7. Lam JC, Ip MS. An update on obstructive sleep apnea and the metabolic syndrome. Curr Opin Pulm Med 2007;13:484-9.

8. Punjabi NM, Polotsky VY. Disorders of glucose metabolism in sleep apnea. J App/ Physiol 2005;99:1998-2007.

9. Viot-Blanc V, Levy P. Sleep apnea and glucose metabolism: the new challenge. Sleep Med 2006;7:538-40.

10. Vgontzas AN, Papanicolaou DA, Bixler EO, et al. Sleep apnea and daytime sleepiness and fatigue: relation to visceral obesity, insulin resistance and hypercytokinemia. J Clin Endocrinol Metab 2000:85:1151-8.

11. Punjabi NM, Sorkin JD, Katzel LI, et al. Sleep-disordered breathing and insulin resistance in middle-aged and overweight men. Am J Respir Crit Care Med 2002;165:677-82.

12. Reichmuth KJ, Austin D, Skatrud JB, et al. Association of sleep apnea and type II diabetes: a population-based study. Am J Respir Crit Care Med 2005;172:1590-5.

13. Harsch IA, Schahin SP, Radespiel-Troger M, et al. Continuous positive airway pressure treatment rapidly improves insulin sensitivity in patients with obstructive sleep apnea syndrome. Am J Respir Crit Care Med 2004;169:156-62.

14. Elmasry A, Lindberg E, Berne C, et al. Sleep disordered breathing and glucose metabolism in hypertensive men: a population based study. $J$ Intern Med 2001;249:153-61.

15. Ip MSM, Lam B, Ng MM, et al. Obstructive sleep apnea is independently associated with insulin resistance. Am J Respir Crit Care Med 2002;165:670-6.

16. Meslier N, Gagnadoux F, Giraud P, et al. Impaired glucose-insulin metabolism in males with obstructive sleep apnoea syndrome. Eur Respir J 2003;22:156-60.

17. Polotsky VY, Li J, Punjabi NM, et al. Intermittent hypoxia increases insulin resistance in genetically obese mice. J Physiol 2003;552:253-64. 
18. Somers VK, Dyken ME, Clary MP, et al. Sympathetic neural mechanisms in obstructive sleep apnea. J Clin Invest 1995;96:1904.

19. Spath-Schwalbe E, Gofferje M, Kern W, et al. Sleep disruption alters nocturnal ACTH and cortisol secretory patterns. Biol Psychiatry 1991:29:575-84.

20. Spiegel K, Leproult R, Van Cauter E. Impact of sleep debt on metabolic and endocrine function. Lancet 1999;354:1435-9.

21. Gottlieb DJ, Punjabi NM, Newman AB, et al. Association of sleep time with diabetes mellitus and impaired glucose tolerance. Arch Intern Med 2005;165:863-7.

22. Zhan G, Serrano F, Fenik P, et al. NADPH oxidase mediates hypersomnolence and brain oxidative injury in a murine model of sleep apnea. Am J Respir Crit Care Med 2005; 172:921-9.

23. Gozal D, Kheirandish L. Sleepiness and neurodegeneration in sleep-disordered breathing: convergence of signaling cascades. Am J Respir Crit Care Med 2005;171:1325-7.

24. Matthews DR, Hosker JP, Rudenski AS, et al. Homeostatic model assessment: insulin resistance and B-cell function from fasting glucose and insulin concentrations in man. Diabetologia 1985;28:412-19.

25. Coughlin SR, Mawdsley L, Mugarza JA, et al. Obstructive sleep apnoea is independently associated with an increased prevalence of metabolic syndrome. Eur Heart J 2004;25:735-41.

26. McArdle N, Hillman D, Beilin L, et al. Metabolic risk factors for vascular disease in obstructive sleep apnea: a matched controlled study. Am J Respir Crit Care Med 2007:175:190-5.

27. Elmasry A, Janson C, Lindberg E, et al. The role of habitual snoring and obesity in the development of diabetes: a 10 -year follow-up study in a male population. J Intern Med 2000;248:13-20.

28. Sharma SK, Kumpawat S, Goel A, et al. Obesity, and not obstructive sleep apnea, is responsible for metabolic abnormalities in a cohort with sleep-disordered breathing. Sleep Med 2007;8:12-17.
29. Davies RJ, Turner R, Crosby J, et al. Plasma insulin and lipid levels in untreated obstructive sleep apnoea and snoring; their comparison with matched controls and response to treatment. J Sleep Res 1994;3:180-5.

30. Lindberg $\mathbf{E}$, Berne C, Elmasry A, et al. CPAP treatment of a population-based samplewhat are the benefits and the treatment compliance? Sleep Med 2006;7:553-60.

31. Coughlin SR, Mawdsley L, Mugarza JA, et al. Cardiovascular and metabolic effects of CPAP in obese males with OSA. Eur Respir J 2007;29:720-7.

32. West SD, Nicoll DJ, Wallace TM, et al. The effect of CPAP on insulin resistance and HbA1c in men with obstructive sleep apnoea and type 2 diabetes. Thorax 2007;62:969-74.

33. Barbe F, Mayoralas LR, Duran J, et al. Treatment with continuous positive airway pressure is not effective in patients with sleep apnea but no daytime sleepiness, a randomized, controlled trial. Ann Intern Med 2001;134:1015-23.

34. Lindberg E, Berne C, Franklin KA, et al. Snoring and daytime sleepiness as risk factors for hypertension and diabetes in women-a population-based study. Respir Med 2007:101:1283-90.

35. Robinson GV, Smith DM, Langford BA, et al. Continuous positive airway pressure does not reduce blood pressure in nonsleepy hypertensive OSA patients. Eur Respir J 2006:27:1229-35.

36. Mediano 0, Barcelo A, de la Peña M, et al. Daytime sleepiness and polysomnographic variables in sleep apnoea patients. Eur Respir J 2007:30:110-13.

37. Sandhu MS, Heald AH, Gibson JM, et al. Circulating concentrations of insulin-like growth factor-I and development of glucose intolerance: a prospective observational study. Lancet 2002;359:1740-5.

38. Moses AC, Young SC, Morrow LA, et al. Recombinant human insulin-like growth factor I increases insulin sensitivity and improves glycemic control in type II diabetes. Diabetes 1996;45:91-100.

39. Morrow LA, O'Brien MB, Moller DE, et al. Recombinant human insulin-like growth factor-I therapy improves glycemic control and insulin action in the type A syndrome of severe insulin resistance. J Clin Endocrinol Metab 1994;79:205-10.

\section{Lung alert}

\section{Alpha-1-antitrypsin deficiency and increased lung cancer risk}

Lung cancer development is a multifaceted process involving environmental and genetic factors, but their intricate interaction and extent of predisposition remains ill-defined. This study investigated the role of alpha ${ }_{1}$-antitrypsin deficiency $\left(\alpha_{1}\right.$ ATD), chronic obstructive pulmonary disease (COPD) and tobacco smoke exposure in lung cancer development in 1856 patients with lung cancer. The two control groups were free of any cancer and comprised 1585 community residents and 902 full siblings of patients. The $\alpha_{1}$ AT alleles were tested in 1443 patients, 797 unrelated controls and 902 full siblings. The carrier rate was $13.4 \%, 7.8 \%$ and $9.9 \%$, respectively.

The findings suggest that $\alpha_{1}$ ATD carriers are at a $70-100 \%$ increased risk of lung cancer, particularly adenocarcinoma and squamous cell subtypes (adjusted for the effects of tobacco smoke exposure and COPD). Depending on smoking intensity, smokers were noted to have a 2-9-fold higher risk of lung cancer than never smokers. The study also confirmed that COPD, which conferred a greater than 6-fold risk of developing lung cancer, is an independent risk factor with an expected population attributable risk of $10-12 \%$.

The study demonstrates complex gene-environment interplay in lung cancer development and indicates the potential benefit in identifying $\alpha_{1}$ ATD carriers who may be susceptible to carcinogens. The possible underdiagnosis of COPD, use of community-based controls and likelihood of ethnic stratification are potential limitations of the study. The authors suggest further studies to examine whether the excess risk of lung cancer in patients with COPD stems from emphysema, chronic bronchitis or both.

- Yang P, Sun Z, Krowka MJ, et al. Alpha1-antitrypsin deficiency carriers, tobacco smoke, chronic obstructive pulmonary disease, and lung cancer risk. Arch Intern Med 2008;168:1097-103

\section{S K Chhetri}

Correspondence to: Dr S K Chhetri, ST2 Medicine, Salford Royal NHS Foundation Trust, Salford M6 8HD, UK; chhetrisk@gmail. com 